\title{
Heutagogy as a Concept of Online Education in Higher School
}

\author{
Larisa Bykasova $^{1,{ }^{*}, \text { Elena } \text { Kamenskaya }}{ }^{2}$, Margarita Krevsoun ${ }^{1}$, and Vladimir \\ Podbereznyj ${ }^{1}$ \\ ${ }^{1}$ Taganrog Institute named after A. P. Chekhov (branch) "Rostov state economic University (RINH)", \\ Initiative Street, 46, 347936 Taganrog, Russia \\ ${ }^{2}$ Southern Federal University, Rostov region, Rostov-on-Don, Bolshaya Sadovaya Street, 105-42, \\ 344006, Russia
}

\begin{abstract}
From the synergistic approach position, an attempt to reflect on the main axiological problems of the online education in higher school in the format of the heutagogy concept, representing the semantic system of the education modern subject regulation and self-learning intentions, is made in the article. In the triad of pedagogy-andragogy-heutagogy, the authors reveal the means, motivation, focus of the subject's learning, teacher's role at each stage of education, they describe the values of the personality, possessing a formative and guiding beginning; having a consistently significant character for a person, which allows expediently organizing an educational process, bearing a controlled nature. The dynamic context of the subject's values development is presented in the article with the knowledge accumulation cumulative process; it is described by the main mechanisms that determine the student's semantic picture appearance. For the pedagogical science institutionalization, the article reminds of the individual social inheritance essential attribute. Verification of the pedagogical knowledge different scale and its growth became possible due to the concept value retrospective analysis from the position of three main directions development: social, theoretical, methodological, which made it possible to answer the main question of technologies: how to discover the semantic intentions of the subject, to reflect them, to initiate their appearance, to transfer into self-actualization mode in heutagogy format.
\end{abstract}

\section{Introduction}

We would turn to the concepts definition, introduced into the canvas of our research. The "pedagogy" concept, following A.M. Novikov, we interpret as a science that studies personally determined, purposeful activity to familiarize the subject with life in the society [1-16].

\footnotetext{
* Corresponding author: moeve-25-moeve@yandex.ru
} 
The andragogy, according to B.M. Bim-Bad, is a branch of the pedagogical science, covering the adult education problems [4, 17-21]. The andragogy is a section of didactics that reveals and develops the adult education principles.

The concept "heutagogy" means the doctrine about the self-education. The heutagogy is rightly postulated by the authors as a doctrine about the self-education, since the heutagogy is a holographic phenomenon, meaning.

1. lifelong learning, that is learning during the whole life, retraining, education in different contexts;

2. learner center learning - the student is active in learning, he chooses the path of development himself;

3. goal-oriented learning - purposeful learning, and its focus is result-oriented;

4. self-directed learning - examines the teacher's role in the organization of self-directed learning.

\section{Materials and methods}

We would consider the typology of three concepts in details, for which we reflect on their essence through the prism of discourse, intentions and determinants [19].

Table 1. Typology of knowledge scientific branches

\begin{tabular}{|c|c|c|c|c|c|}
\hline No. & Branch & Purpose & Discourse & Intentions & Determinants \\
\hline 1. & Pedagogy & Children learning & Cognition & $\begin{array}{l}\text { Involvement in the } \\
\text { cognition process }\end{array}$ & $\begin{array}{c}\text { Work under the } \\
\text { teacher's } \\
\text { guidance }\end{array}$ \\
\hline 2. & Andragogy & $\begin{array}{c}\text { Educated person } \\
\text { establishmnet }\end{array}$ & Metacognition & $\begin{array}{c}\text { Knowledge } \\
\text { unfolding; } \\
\text { homo cognoscens } \\
\text { formation }\end{array}$ & $\begin{array}{c}\text { The subject's } \\
\text { independence in } \\
\text { search for } \\
\text { information, its } \\
\text { analysis, } \\
\text { synthesis }\end{array}$ \\
\hline 3. & Heutagogy & $\begin{array}{c}\text { Subject's self- } \\
\text { learning }\end{array}$ & Episystematicity & $\begin{array}{c}\text { Realizing the } \\
\text { gained knowledge } \\
\text { in practice }\end{array}$ & $\begin{array}{c}\text { Subject's self- } \\
\text { determination }\end{array}$ \\
\hline
\end{tabular}

We would turn to the data analysis in our table. The pedagogy mission is to educate children. The pedagogical science purpose is to develop and to justify the system of the individual's education and upbringing; to predict the upbringing processes, to develop of the subject education and training, while the education discursive picture is characterized by the subject's desire for cognition, the student's active involvement in the cognition process under the teacher's guidance. In the pedagogy, an important role belongs to the teacher, since it is he who determines the educational trajectory, the student's progress speed of, the learning process didactic support [5].

The andragogy mission is the homo cognoscens establishment (a person who knows and is conscious). The andragogy goal is to educate adults, i.e. this is

- independence and autonomy of the trainees;

- using your own experience and attracting the existing experience of other people;

- expanding the range of methods for obtaining knowledge (idealization, formalization, synthesis, modeling, abstraction, analogy, deduction, induction, etc.);

- educational practice different focus, i.e. subject's orientation to solving emerging problems;

- increased self-esteem of the education subject due to the recognition of his academic success; 
- comfortable learning conditions for the subject (creating the psychological atmosphere, relaxation and harmonization);

- logical completion of the learning mission and the formation of metacognitive skills in the education subject [15].

The heutagogy mission is subject's self-learning. The heutagogy goal is self-education, that puts the epistemic nature of this process at the forefront, which today is of particular importance, since it determines the realization of the education subject self-determination. In the heutagogy format, all trainees are interdependent and able to manage their learning process $[11,49]$. The teacher's task as a tutor is to create conditions for the subject's learning, to provide certain resources, and to supply with the learning process didactic content. The learning process in the heutagogy can be revised, i.e. it is not to be once and for all given, it does not have a constant goal, but it can be initiated by the subject, which resembles the information drift situation, so it can be stated that the learning focus in the heutagogy is rather blurred [12,].

We would try to figure out what this means.

1. The trainee goes beyond the boundaries of the discussed problematics;

2. The subject learns proactively (with the focus on what is important; he acts here and now with awareness of his future needs; he is able to choose between an active or passive life position; he also realizes his deep values and goals) [1].

The motivation in the heutagogy is the subject's hidden resources: the desire to learn, the creativity, the aspiration for the self-development. The teacher contributes to the formation of students' interaction and cooperation skills.

In the XXI century, we note the scientific knowledge expansion, the transformation of the socio-economic, cultural, socio-political structure, the techno-structural changes. Besides, the second decade of the XXI century is marked by the epidemics and pandemics emergence, therefore, such form of the education as distance education, e-learning, selfeducation of the subject has become especially in demand [21]. The schools and universities transition to the distance learning format required the existing pedagogical concepts revision, aimed at developing the modern methodological approaches to work in the heutagogy format, to the new psychological and pedagogical phenomena study, arising in conditions of the digital technologies introduction, and the reflection of the domestic education entire system scientific and educational potential.

The "potential" concept includes educational means, resources, and reserves. Each potential element is hypothetically capable of influencing the various functions performance (upbringing, education, socialization, etc.). The scientific and educational potential successful is intended to ensure the subject's conflict-free existence in the artificially created educational (upbringing, aesthetic, sports, communication, etc.) environment, regardless of its state (upward development trend, stagnation, plateau, downward trend).

In the selected problematics format, we would dwell on the educational environment characteristics - the structure, possessing coherence, integrity, controllability, depending on its educational, educational, informational and other resources saturation [2].

For our research, it is also important to consider the information environment phenomenon, as the most demanded in the subject's work in the distant mode. This type of environment is saturated with the intellectual structures; it has the information labels, stimulating the individuals' activity, and it involves not only the subject's neural network in the individual educational trajectory design, but also the learner's limbic system (i.e., the brain system responsible for the emotions in the network) [10]. 
The information environment includes several components: content, technologies, educational process methods, subjects, environment, however, we consider the main human-centered experience of the environment, which can be represented in the form of the formula: $\mathrm{HCX}=\mathrm{UX}+\mathrm{ID}$, where $\mathrm{HCX}$ is the human-centered experience; UX is user experience: ID is instruction design.

The modern information environment architecture may hypothetically look as follows.

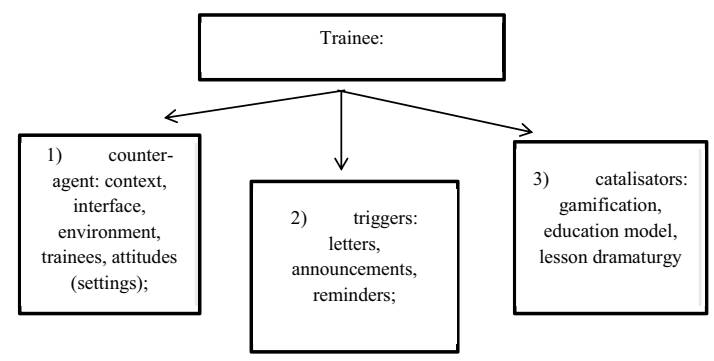

Fig. 1. Information environment architecture

In the online learning format today the information environment is

1) the platform, where the educational process takes place;

2) the dynamic zone with its own geometry that changes its characteristics;

3 ) the target audience, where the focus is on the teacher's recommendations to the education subject [6].

The subject successfully uses knowledge, skills and abilities obtained in the artificially created information environment for self-development, self-study, self-learning, selfeducation [22,].

The synergistic approach application to the phenomenon study will help us to find out the most important purpose of the heutagogy. It is not the created system of education, they are not the tools used in this system, but it is the self-education of a person with his needs, tactical and strategic goals and objectives, the main of which is the individual selfimprovement.

\section{Results}

The main problematic question of our article is the following: what are the features of the online education concept in higher school in the heutagogy format? To answer this question, we'd consider three most important theses, in our opinion: the classical university role and tasks; the teaching staff training unification and standardization; using the experience of other universities in the work of their own university.

1. A classical university has always been distinguished with such characteristics as: the fundamental training (managerial elite), the different role formation for entering the profession (highly intelligent personnel), the flexibility and individuality as the basis of the education quality (educational tracks), the student training models (synthetic samples). In the 90 s of the last century, the classical university education dysfunctional state was outlined, which led to its stagnation and partial regression, as a result of which the studentship was disoriented and focused on the narrowly applied aspects of the future labor activity, on quantitative (not qualitative) indicators in the teaching and doing science [20]. 
As a result, we note that the university has partially lost the scientific and methodological center function for the education corresponding profile and insufficient the fundamental and applied scientific research implementation.

Today, as never before, the words of X. Ortega-and-Gasset are relevant: "Maintaining the modern civilization level is prohibitively difficult ... and this skill is beyond the reach of those who have learned to use some of them" [18]. It is difficult to argue with the classical author opinion, since we clearly understand that the fundamental foundations abandonment of any scientific discipline in favor of the certain applied aspects that guarantee quick profits, will lead to the cultivation of "villadom" at the university. The behaviorism and populism, as known, does not contribute to the education development - the space of the structurally incomplete practice of thinking, but they only strive to replace this process with learning.

The founder of the Berlin University A. Humboldt said in due time: "The university is the process and product unity, it is an institution that produces knowledge about culture (during the scientific research) and it produces culture (in the process of learning)" [17]. That is why a modern domestic university returns to the education fundamental nature, focusing at the same time on the intellectual potential of the leading universities in Russia, that is on the classical universities.

2. The second important aspect of the studying problem is the teacher's training. The teaching staff training unification and standardization is the discussion subject among the academic scientists and practitioners. We consider the teacher training to be the strategic resource of our education system. The Russian Academy of Education has developed a number of initiatives, aimed at the modern teacher training: hybrid forms of teacher training, knowledge technologization, flexibility and individual approach in high-quality teacher training, student training model - training a researcher, digitalization module support for the students in the distant learning mode, catching up with the curricula [23].

The curriculum and work programs of the university disciplines take into account various aspects in the specialists training:

- historical, economic, sociocultural situation;

- cultural development stage;

- mixed education;

- work with new software;

- convergent thinking development, etc. [9].

Accounting these aspects makes it possible to provide the trainees with the new "crosscutting" competencies, which "sew" all education levels, and they will be in demand by the employer in the next 10-15 years. The acquired system of competencies will allow the education subject to recognize the patterns and to see the meaning between the knowledge areas, to develop the algorithmic thinking in trainees, and to turn the learning process into the decision-making process.

In the heutagogy format, we'd consider the factors, providing a "quantum leap" in the new competencies acquisition by students. This is the online platforms creation and coordination, the network security support, the educational process maximum automation, the navigation skills formation in the information flows, a large proportion of the project and independent work, etc., which will help to prevent the emerging risks while introducing the digital education, deciding some important tasks during the pandemic:

1) educational process informatization;

2) the modern teacher intellectual potential, erudition and cognitive thinking application;

3) ensuring the psychological readiness to change the scientific, educational, methodological, educational work; 
4) the social surfing implementation;

5) overcoming the mental anorexia, dysthymia, addiction of the teaching staff;

6) the most favored nation treatment creation for the committed teachers - the heads of the scientific schools;

7) the teachers' and students' methodological practice reflection and the new practices subsequent multiplication by the teaching staff in the educational process: cultural and educational research projects; scientific and practical conferences; scientific schools, symposia, etc.;

8) using the Internet capabilities in the modern higher school (various platforms that create the most favored regime in the synchronous / asynchronous interaction organization between the subject and the object of the learning process); the unproductive level (adaptive); the medium productive level (local modeling); the productive level (systemmodeling knowledge of students); the highly productive level (system-modeling activity and behavior of students);

9) mastering the pedagogical activity: the unproductive (reproductive) level;

10) the teaching staff permanent education with the different.

In the modern conditions, the subject's pedagogical activity functional features have become more prominent: the diagnostic function (the teacher's readiness to study the characteristics of training, student learning); the orientation-prognostic function (identification, assessment of the educational activities prospects by the teacher, its phased goals and objectives analysis, the probable results anticipation); the informational and explanatory function; the communicative and stimulating function (suggestive abilities, empathy); the constructive and design activities (the pedagogical interaction building strategic directions); the teacher's organizational activity (the students' actions activation, aimed at achieving the educational results) [13].

3. For the heutagogy successful development, it is important to use the other universities experience in the work of their own higher school. The Russian universities reflect on the universities' experience in other countries, the academic development various models and practices in foreign universities, the strategic initiatives and, after the appropriate analytical and adaptation procedures, they extrapolate the best foreign models into the domestic education practice.

To discuss the foreign countries' experience, we'd dwell on the definition of the "academic development" concept. Depending from the country, they talk about the academic development, the education development, the staff development, and the career development [3]. The common thing in all definitions is to support the teachers in realizing their goals and to promote the university goals' achievement. The importance of the concept is evidenced by the fact that each of the universities, we examined, has programs aimed at developing the subject's pedagogical skills. For example, in Sweden, the role of the government agency for the innovation systems is to ensure more effective interaction between the universities, the research institutes and the industrial companies, as well as to strengthen the support for the universities in the process of the research results commercializing. In Sweden, the universities have received the right to conduct the innovative activities with the various forms of cooperation between the universities and business: the creation of consulting organizations and forums, the divisions that consult on the economic and legal issues, and holding companies.

The United States has adopted the National Technology Education Plan, focused on constructing the student-centered higher education ecosystem. The Creating American ecosystem has certain features:

-assessment of the forms, types of education, the subject's future career;

-learning process financial transparency support; 
-adaptive-targeting support mechanism application for the trainees;

- providing an opportunity for the students to independently determine the training time and format;

-quality educational platforms and resources availability;

-educational networks creation to support the various forms of learning.

In the UK, the practice of inviting the representatives of universities by the Ministry of Innovation to develop the model contracts, aimed at transferring the ownership of the intellectual activity results in the field of innovation, is widespread. At the University of Durham, a variety of the academic development consultations are available to the teachers. The list of consultations types includes, for example, monitoring the teaching process and drawing up a confidential review, developing the skills of the subject's scientific leadership, working out the educational strategies for the faculties and departments. The Cornell University has launched an educational innovation program that is interesting for a Russian teacher in terms of methodology, visualization and demonstration of results. The university has developed a website, which is a pool of the methodological developments, providing the university teachers with a quantum leap in the quantification strategy logic.

Germany, Australia, New Zealand and France have adjusted their national educational plans in the field of higher education, taking into account technological and technical innovations, as well as the conditions of distance learning during the pandemic period [8].

\section{Discussion}

The modern education digital transformation is a key element of the heutagogy. Of course, the Internet of "everything", existing today, poses many questions for the teachers and students about the digitalization significance, about its impact on the mankind development.

We see this problem the urgency in various aspects: these are ethical regulations of the subject's activities, aimed at developing the speed of decision-making, mastering the skills of designing their activities; increasing the level of modern person responsibility in the system of requirements for the education subject of the XXI century, and a new format for the professional educational programs development.

The reflected phenomenon importance is evidenced by the attention of the scientific community to various aspects of the digital education:

- The local computer networks' didactic potential is reflected in their works by A. Lohr, M. Stadler, M. Sailer [14];

- The computer networks functions in the educational process are investigated by U. M. Dholakia, R. P. Bagozzi, L. K. Pearo [7];

- The social networks' importance is studied by V. C. Reyes, Ch. Reading, S. Gregory [19];

- The electronic teaching aids role in the modern educational process is analyzed by P.D. Wiens, K. Hessberg, J. De Coster [23];

- C. M. Tham, J. M. Werner are engaged in the domestic networks' content analysis [21];

- Reengineering of activities in the educational sphere based on the network is considered by N. A. Barinova, E. V. Karunas [3];

- The collaborative network activity pedagogical design is considered in their works by R. Straub, S. Kulin, T. Ehmke [20].

For the organization of self-study and self-development, it is important to take into account both the positive and negative sides of the network. The network's positive qualities include multitasking, changing the type of thinking, expanding the subject's 
educational capabilities, using a wide range of the teaching aids and sources of narratives, etc.

From the group of the network's negative aspects (social skills lowering, screen addiction, etc.), in our opinion, the most destructive aspect is the introduction of certain untested technologies into the education practice. Namely this fact can plunge the education subject into a stalemate in the material's independent development.

For the heutagogy, it is important to consolidate the efforts of homo cognoscens in assimilating the amount of information, having the exponential character in the XXI century; in the externalization and internalization, in the acquired knowledge combination; in modeling the new information polygons. For a "person who is conscious", a set of competencies, other than those already available, is needed, which are necessary for a conflict-free existence in an information society.

\section{Conclusions}

Summarizing the above said, we'd note that as a result of these problems' study, we have identified:

- the heutagogy value, modifying the modern higher school methodological basis, providing the subject's self-education with the information platforms structure transparency, the their didactic content openness and the content relevance, the high speed of its processing in the individual mode, which indicates the subject's thinking development in the process of self-learning;

- the trends in the pedagogical education development in the information technologies dynamic implementation context in the educational process, the main of which is the digital education as a general direction of the individual socio-cultural development in the heutagogy;

- the digital education importance, contributing to the education system transformation on the basis of the innovative technologies further evolution; creation by the subject of the educational, research activities and development individual trajectory of the subject;

- the factors in the modern digital education development: the exponential growth in the amount of information; the Internet educational potential; the education personalization, a park of training devices and simulators; the information society instrumental potential formation;

- the digital education role as the crisis management mechanism in modeling the information polygons; the situational analysis as a method of obtaining the factual information;

- the significant exhibiting apperception imprinting as an integral part of the educational subject's project, team, problem learning strategy with highly developed emotional intelligence;

- the homogenization process futuristic nature as a new stage in the modern university existence;

- the education modern subject orientation in the heutagogy, requiring further development of pedagogical projections, reflecting the influence of postmodern ideas on the transition to an education system with a relatively stable structure that ensures the improvement of the subject's spiritual culture and self-development, thanks to the educational process informatization and information support introduction.

\section{References}


1. S. Abraham, Crafting a pedagogical third space in a transnational teacher education project. Teaching and Teacher Education, 2(9), 44-53 (2020) doi.org/10.1016/j.tate.2020.103207

2. K.V. Andreeva, L.V. Bykasova, Environment-oriented education in a modern University. Modern problems of science and education, 6, 329 (2013)

3. N.A. Barinova, E.V. Karunas, Individual educational program design as a consequence of FSES realization. Kazan Pedagogical journal, 3(110), 70-75 (2015)

4. B.M. Bim-Bad, Pedagogical encyclopedia (Moscow, Big Russian Encyclopedia, 2012)

5. M.V. Boguslavskij, The concept of higher education development in Russia. World of education, 5, 17 (2016)

6. L.V. Bykasova, E.A. Belyak, V.V. Podberezny, M.V. Krevsun, Digital education as a System Strategy for Saving the nation. ARPHA Proceedings 3, 355-368 (2020) doi:10.3897/ap.2.e0. 793.

7. U.M. Dholakia, R.P. Bagozzi, L.K. Pearo, A social influence model of consumer participation in network-and small-group-based virtual communities. International Journal of Research in Marketing, 21(3), 241-263 (2004) doi.org/10.1016/j.ijresmar.2003.12.004

8. N.B. Ellison, Social network sites: Definition, history, and scholarship. Journal of Computer-Mediated Communication, 13(1), 210-230 (2007) https://doi.org/10.1111/j.1083-6101.2007.00393.x

9. D. Gibson, T. Broadley, J. Downie, P. Wallet, Evolving Learning Paradigms: ReSetting Baselines and Collection Methods of Information and Communication Technology in Education Statistics. Educational Technology \& Society, 21(2), 62-73 (2018)

10. B. Gleason, S. Gillern, Digital Citizenship with Social Media: Participatory Practices of Teaching and Learning in Secondary Education. Educational Technology \& Society, 21(1), 202 (2018)

11. E.N. Kornilova, Reforming education and science in Russia as manipulating with the mass consciousness. Moscow State University Bulletin. Series 18. Sociology and Political Science, 26(4), 48-75 (2020)

12. A.V. Lubkov, S.D. Karakozov, Digital education for the digital economy. Informatics and education, 8, 3-6 (2017) doi: 10.18384/2310-7219-2018-3-25-36

13. M. Luskova, M. Hudakova, Approaches to Teachers' Performance Assessment for Enhancing Quality of Education at Universities Procedia. Social and Behavioral Sciences, 10, 78-89 (2013) doi: 10.1016/j.sbspro.2013.12.053

14. A. Lohr, M. Stadler, M. Sailer, On powerpointers, clickerers, and digital pros: Investigating the initiation of digital learning activities by teachers in higher education. Computers in Human Behavior, 2(6), 96-104 (2021) doi: $10.3102 / 0034654310393361$

15. L.V Mardahaev, Subject-epistemological foundations of social pedagogy. Pedagogical education in Russia, 12, 244-249 (2016)

16. A.M. Novikov, Pedagogika. Dictionary of the system of basic concepts (The Great Russian Encyclopedia, Moscow, 2013)

17. N.G. Osipova, Role of the classical university in elite reproduction. Moscow State University Bulletin. Series 18. Sociology and Political Science, 23(4), 9-31 (2017)

18. X. Ortega y Gasset, Revolt of the Masses (Ast, Moscow, 2016) 
19. V.C. Reyes, Ch. Reading, S. Gregory, Integrating ICT into teacher education programs from a TPACK perspective: Exploring perceptions of university lecturers. Computers \& Education, 20, 69-78 (2017) doi: 10.1016/j.compedu.2017.07.009

20. R. Straub, S. Kulin, T. Ehmke, A transdisciplinary evaluation framework for the assessment of integration in boundary-crossing collaborations in teacher education Studies in Educational Evaluation, 13, 104-121 (2020)

21. C.M. Tham, J.M. Werner, Designing and evaluating e-learning in higher education: A review and recommendations. Journal of Leadership \& Organizational Studies, 11(2), 15-25 (2005) https://doi.org/10.1177/107179190501100203

22. A. Twissell, Modelling and Simulating Electronics Knowledge: Conceptual Understandin and Learning through Active Agency. Educational Technology \& Society, 21, 111-123 (2018)

23. P.D. Wiens, K. Hessberg, J. De Coster, Using a standardized video-based assessment in a university teacher education program to examine preservice teachers knowledge related to effective teaching. Teaching and Teacher Education, 4(12), 98-117 (2013) 